\title{
QUILT: a case study in the impact of a staff development programme
}

\author{
Kevin Donovan and Daniel Atwere \\ Further Education Development Agency (FEDA) \\ email:kevin_donovan@hotmail.com
}

QUILT ('Quality in Information and Learning Technology') is a multifaceted staff development programme which was designed to make all college staff enthusiastic about new technology and to help them incorporate it in their work. The programme has been designed and led by the Further Education Development Agency (FEDA). FEDA's work is described on its web site (http://www.feda.ac.uk). QUILT has its roots in the Higginson Report in which the Further Education Funding Council set out a vision for information and learning technology with staff development as a priority. The English and Welsh Further Education Funding Councils have contributed around $£ 2 m$ to what became a f5m five-year programme. The continuing emphasis of QUILT has been on the 'learning' in information and learning technology.

This is a positioning paper, the QUILT programme provides a formative case study example of funding targeted at all types of college staff. The paper illustrates the training and development methods used in the QUILT programme, analysing the programme's success during its first two full years of operation, and linking the successful design of QUILT to other initiatives in the sector.

The QUILT model has influenced the form of the National Learning Network (NLN), as described elsewhere in this edition. Reference to the NLN programme, comparisons with the British Educational Communications and Technology Agency (Becta) surveys on which the NLN was based, and the evaluation of the NLN to date will help readers to supplement the analysis here. Details of the Becta survey and associated related material can be found at http:llferl.becta.org. uk. The NLN evaluation has a dedicated. Website (http:l/www.shu. ac.uklnln) which is a useful and developing resource for those interested in the efficiency and effectiveness of learning technology. $A$ version of this paper (with more detailed statistics) is available there. 


\section{Introduction}

The QUILT programme was designed and delivered on the basis of a major FE sector survey of 15,000 college staff and a series of consultation events during 1996 . The survey results were included in FEDA's submission for funding for the QUILT programme to the FEFC. The events, to which a senior manager and the member of staff responsible for IT in every sector college were invited, took place in every English region and in Wales. These established training and other needs, the extent of technological readiness in colleges, and preferred training methods. QUILT was launched in Wales in 1996 and in England during the following year. Its design has been adjusted to account for a follow-up survey in 1998 and an impact study in 1999. Both of these (like the original survey report) were unpublished FEDA documents; data from them was used in internal reports to the FEFC and its Information and Learning Technology Committee (FEILTC). Other evidence for change was provided by (for example) comments from delegates at events and from members of the FEILTC. Subsequent initiatives also accounted for adjustments to the programme to avoid duplication and to maximize synergy.

\section{The QUILT programme in practice}

The submission from FEDA approved by the Funding Councils covered seventeen activities. These included training sessions, involving day and residential events ranging from ILT awareness to use of the Internet, the use of ILT in specific programme areas and Web design. The events were attended by senior managers, tutors, technical and support staff, some of whom were targeted with information on specific events. College governors (crucial for effective strategic development) have not attended in large numbers and a multiple media training pack designed for them will be available soon. As colleges have run more in-house training to match greater IT investment, the emphasis has been on specialist events (eg Web and intranet design and ILT in programme areas).

The programme also offered consultancy on IT issues on a subsidized basis. Although this initially did not meet with great demand, the recent requirement for colleges to produce considered ILT strategies in order to secure any NLN benefits has produced a number of requests. Alongside this, the programme has offered publications (all referenced on the FEDA Website) in a range of media, including one FE CD containing resources and ideas for ILT use, with free Internet access. Print publications have also been very popular. The ILT Planning Handbook is out of print, but the others are still available including a Web design manual, which has sold in large numbers. Some of the publications (such as those on ILT learning styles) are accompanied by free Internet-based resources such as Powerpoint slide sets. Information services supported the programme (originally a QUILTlink co-ordinator), answered sector queries by email and telephone and offered a planning material exchange; this has been replaced by Web-based services.

Perhaps the major achievement of the programme has been in supporting college-based action projects. Groups of colleges have received small amounts of money on a matched basis to undertake developments in a range of ILT areas, such as key skills, intranet development and online tutoring. The project topics have reflected the move towards greater use of distance and online methods, and the success of UK colleges in related staff training. The projects absorb one-third of the QUILT budget, which is returned directly to 
colleges for staff release. The report Websites and other material developed as part of the QUILT programme show the rich project outcomes, some of which are described below.

QUILT quickly became part of the fabric of the further education sector, with excellent demand for its activities. During a full year of the programme, fifty-five QUILT events involving 1,200 staff (including governors, principals, senior managers, curriculum staff and business support staff) were delivered, mainly in sector colleges. The first thirty-eight Welsh and English QUILT college-based action projects were completed, reported on the Website and disseminated via events and publications; a further twenty-four projects (mainly consortia) were started, developing staff in a range of ILT applications. A total of 350 colleges and 2,000 senior managers were registered members of the QUILTlink information service, and received newsletters and remote support.

All colleges received QUILT event prospectuses and copies of QUILT newsletters. Over 3,000 copies of the first QUILT publications were sold; all were translated into Welsh and made available on the Website. Hundreds of hours of learning material provided by FENC (the Further Education National Consortium) covering a range of programme areas were translated into Welsh (and made accessible via the Internet) and the first QUILT CD was produced.

In other work by FEDA staff, research on IT key skills and on learning with IT was completed and published. There was also an investigation into the IT-related accreditation routes followed by college staff. Further research initiated an analysis of IT solutions for student tracking and tutorial support - vital issues in the promotion of 'lifelong learning'. Case studies on the efficiency and effectiveness of ILT were produced in nine colleges and published on the Web, as one of FEDA's contributions to the Further Education Resources for Learning (FERL) programme. These studies, which will be published on CD soon, are referred to below. In an associated development the first two winners of the FEDAsponsored Association of Colleges Beacon Award for the best college ILT staff development have exemplified strong senior management support and the involvement of staff right across colleges.

\section{What has QUILT achieved?}

QUILT has been well received by the'FE sector. In many ways it has entered professional consciousness with (for example) some colleges using the term 'QUILT' as a synonym for all IT activity or producing 'QUILT' newsletters. The programme has also received favourable press mention and references have appeared in ministerial and other official speeches.

Respondents to the 1998 survey (an internal FEDA document, as noted above) expressed strong satisfaction with all categories of QUILT activity. During 1999, the programme was refocused. For example, a forthcoming $C D$, video and print material will help college governors with the crucial task of strategic planning for IT. Events have been concentrated on higher-level activities such as Web skills and the development of standards for ILT materials. Some events are now located in an adult education college with residential facilities. A large number of laptop computers were acquired for transport to and use in colleges where most events take place. The outcomes of the development projects have been consolidated and disseminated, and reports of all completed projects are available via the Website. 
QUILT in Wales illustrates a number of interesting aspects of ILT development, apart from the fact that the small number of colleges has allowed all to participate in events and projects. Here, from the outset, all colleges benefited from access to JANET. The planning for a 'digital college' in Wales has also involved elements from the QUILT programme. All colleges have received free membership of NILTA as a result of FEDA intervention. The Wales QUILT manager negotiated with FENC the provision of hours of learning material which has been translated into Welsh and made available via the Internet. An annual prize is offered for the best Welsh college Website.

\section{The impact of QUILT by 1999 and in 2000}

An impact study in 1999 (an internal FEDA document, unpublished to date) was based on surveys of college staff who had used QUILT services and of those who had participated in QUILT projects. The extracts below concentrate on QUILT activities linked to events and college projects - at a time when QUILT was less than two years old in England and under three in Wales. The study shows, for example, a growth in attendance at ILT events by respondents (less than 1 per cent in 1996; nearly 75 per cent in the last full year).

In responses about what they had gained from attending events, the most positive reactions included the following quotations:

- Learning about new technologies and how they could be used further to enable and empower students in particular.

- Case studies offering practical ideas, which can be applied to our own circumstances.

- Enabled me to see the way forward in my own college.

- The idea that we could do the same at our college.

- The positive attitude and enthusiasm of the speakers.

- Looking to the future, examining changing roles and advice on overcoming problems, apathy and even hostility relating to ILT.

The most negative reactions (and an indication of the needs that the NLN would match) were:

- Not having time to examine and experiment with different technology as much as I would have liked.

- Difficulties of technical issues in relation to implementing ILT.

- The feeling that my own limited resources would not be able to afford anything like the equipment on offer.

- Not having definitive goals for progress - everything is changing so rapidly.

Clearly, however, many staff have been encouraged to use technology by exposure through the programme. One survey question revealed major increases in the use of specific applications before and following attendance at QUILT events. Use of CD-ROMs was up by almost 70 per cent, Internet use was up by almost 30 per cent, email by 40 per cent, and Powerpoint by over 30 per cent. There was little change in the use of video conferencing. 
Perhaps the most fundamental responses were those indicating changes in college ILT/ICT strategies following attendance at a QUILT event. The following are some examples of answers to the related question:

- It has evolved and we are now pro-actively pursuing ILT.

- IT is now being used as a learning resource rather than just an administrative/MIS tool.

- We are no longer planning to write our own learning packages on CD-ROM. The course I went on backed up this decision.

- We updated our ILT strategy with the assistance of a QUILT consultant.

- Visits to QUILT events gave us an insight into possibilities for inclusion.

- The college is much more aware of new technology and the need to improve its market reach. We are now setting up centres outside the college.

- There has been an increased emphasis on ILT staff development needs and increasing awareness of the need for whole-college approaches.

The responses indicate the scale of ILT development already taking place in colleges and it can be seen that in some colleges ILT strategies are clearly set within development planning cycles.

In terms of the actual skills developed from QUILT events, although there was still some way to go, all respondents agreed that the following had been enhanced to a considerable degree:

- confidence in using a computer;

- efficiency in using a computer;

- understanding computer jargon;

- applying IT day to day;

- embedding ILT in programmes;

- developing in-house materials;

- facilitating and assessing learning;

- improving flexibility of learning;

- giving access to a variety of learning resources;

- dissemination of information.

When it came to limitations after attending events, the following are examples of responses given:

- time to put new ideas into practice;

- lack of, and availability of, resources;

- lack of self-confidence and up-to-date knowledge in applying the technology in a classroom setting; 
- access to equipment;

- access to the technology is limited in my work area but has improved this year with a staff ILT room. However without further training I do not have the confidence to develop in-house materials.

Answers about what further training staff needed included the following:

- teaching with ILT as well as more awareness of practice in FE/HE;

- training about the 'why' as much as the 'how' to create and adapt materials;

- increasing awareness of new developments in assistive technologies and equipment;

- not one specific area, but a constant sharing of new ideas is useful;

- more networking, contacts needed with other colleges;

- in an area, such as technology, things are changing and developing so quickly that it seems necessary to hold events more regularly in order to stay up to date;

- more visits to individual colleges would be useful - 'QUILT days'.

It will be noted that most, if not all, of these suggestions have been incorporated in, for example, FERL (seminars in ILT 'Beacon' colleges) and the NLN.

The impact study also focused on QUILT-funded projects and their impact within the relevant institutions. It should be noted here that over the three years, for example, most of the English projects have been based on consortia rather than single colleges. Responses in the first year of projects such as, 'This is the best staff development these colleagues have ever experienced', gave the team confidence to continue giving priority to this activity.

One question in the survey asked the respondents to comment on the status of their project after completion. There are more favourable comments than there is space to reproduce them but one single quotation gives an adequate flavour:

The project is continuing very well across the colleges who took part in the collaborative activity. We have developed the QUILT theme and included the project in our development strategy. This project won a 1998-9 Beacon Award for ILT developments most definitely an extension of the original QUILT bid.

A visit to the project reports on the Web - and to the work represented there by other sites - provides a rich source of information. At least two of the original projects have had major growth and impact. LeTTOL (Learning to Teach OnLine, at http://www.sheffcol. acuk/lettoll) has grown beyond its original consortium of South Yorkshire colleges to reach students in many countries. Over 400 people (teachers, lecturers, trainers, materials developers, and academic or technical managers, from the private and public sectors) have completed LeTTOL to date. It won the 1999 Becta Beacon Award for ILT to support effective learning. The scheme equips participants to teach learners online, support learners using email and conferencing, manage online learning provision, employ the Internet as a resource for teaching and learning, and apply appropriate learning methods in the design of online learning materials. The majority of course activities, tutor support, peer interaction and assessment, take place online. The programme is accredited by the 
UK's National Open College Network. Surrey Net (http://www.surreynet.org.uk/) has spread its reach beyond colleges to schools and other public and private sector organizations. It is described as the 'intranet for the Surrey education community' and provides information, advice communication, materials and discussion forums for users.

The first report of the NLN evaluation team included five example projects reflecting successful outcomes from QUILT projects and colleges investigated by FEDA as part of research for FERL. What follows are very brief extracts, included to give a flavour of achievements. All these projects have been catalysts within the individual colleges and consortia and the actual change has generally been greater than originally anticipated in terms of funding and meeting objectives of participation, retention and achievement.

City of Bristol College, in partnership with the College of Care and Early Education and Bristol City Council Community Education Service, completed a QUILT project concerned with the delivery of learning programmes through online learning. None of the organizations had previously used online learning to any significant extent. The partners found that the reaction to the course was very positive with all college staff benefiting from both the content and the experience of being an online student. The QUILT project highlighted that, in order for a tutor to be effective in supporting online learning, structured training must be provided.

Wigan and Leigh College, Liverpool Community College and Knowsley Community College looked at the use of video conferencing to enhance curriculum delivery. They aimed to raise awareness of how video conferencing can be used in teaching and learning, to provide staff development in all three institutions, to share curriculum expertise via video conferencing and to explore the potential use of video conferencing for nontraditional groups of students. The project team found video conferencing to be effective, in terms of time-saving, communicating at a distance and successfully sharing information, but difficult from a social perspective and because of the great amount of preparation required. The team agreed that it was a better communication method than teleconferencing.

Askham Bryan College, specializing in land-based vocational education for both $\mathrm{HE}$ and FE, used FERL funding to discover the practical uses for ILT in applied plant sciences. The project was needed due to the widespread restructuring of college staffing and curriculum. This was resulting in fewer teaching staff, but also more courses with flexible delivery modes, shorter contact hours and longer self-study periods. The college also wanted to achieve economies of scale whilst maintaining quality. For example it was found that the use of ILT encouraged students and tutors to interact both on and off campus. Students who were unable to get to college could enjoy participation. There was initial student hostility but the systems have been effective in supporting students with learning disabilities; one severely dyslexic student used 'talking diagrams' to great effect. Additional flexibility allows tutors to respond more easily to specific student needs, whether that need is the notes from a missed lecture or specialized learning support.

SE Essex college completed a project looking at the problem of establishing what was called a fully interactive learning network. The college identified a number of limitations in their current arrangements for student management systems. A college-wide intranet, the proposed solution, must enable tutors to develop academic work such as course plans, 
assignments and other materials on the administration network and to be placed securely on the academic network. It should also allow academic progress to be monitored so that electronic course plans can direct individuals to relevant assignments and suitable course materials. Email allows contact between tutors and students particularly to send assignments and assessments securely. It also provides another route of communication and allows simple updating of student records directly into the database so that staff and individual students can access it. The college has set itself a number of long- and shortterm goals including the introduction of interactive course plans, and the ability for students to email assignments to tutors. Most importantly the college expects to see reductions in costs through more effective deployment of teacher and teaching support roles.

The TROJAN project is a partnership among all nineteen West Yorkshire colleges. It sought to maximize the impact of new technology on small and medium-sized enterprises (SMEs) in the sub-region. Through collaboration the colleges were able to acquire costeffective connectivity and good Internet access. The network was implemented quickly and has proved an efficient and fast solution to connectivity requirements. Another successful part of the project was the development of staff training in relation to both technical and curriculum issues, where staff have shared materials, venues and solutions. The project produced a series of outcomes, such as an assignment framework and common questionnaire, which have been used extensively outside the college. The project fostered a 'champions' scheme.

The influence of QUILT was cited in the decision to devote part of the NLN funding to innovative ICT projects. The first round produced around 170 quality bids, from which 12 were chosen to begin operation in colleges in the summer of 2000 . Details will be found on the planned NLN Website (http://www.nln.ac.uk). The project descriptions indicate in part how far the FE sector has moved since QUILT set a base line just four years ago. The projects have a range of aims covering support for more flexible learning, the management of such flexibility, and the application of a number of emerging technologies in the context of a radically changing lifelong learning environment.

\section{Conclusion}

In conclusion and summary, what do we know about ILT staff development on the basis of the QUILT experience and its menu of activities? A successful programme must relate to the overall mission of an organization and, to do this, it should include all staff and be part of a coherent approach, which embraces policy, strategy and operation. Within this wider approach small-scale action projects produce results: staff are motivated by involvement and outcomes often exceed what might be expected from small investment. Training and consultancy can come in many guises (relevant events, peer support and so on), but they breed enthusiasm if this is harnessed and given continued resources over time. Similarly information and inspiration can come in a variety of media but must be linked to practical applications: staff constantly seek ways to make their work more interesting and productive and the experience of the QUILT programme is that exposure to new ideas can be infectious. 